\title{
Speciation of technogenic radionuclides by varying parameters of the sequential extraction procedure for model and actual contaminated samples
}

ALEKSANDRA RZHEVSKAIA, ANNA FADDEEVA, ANNA SEMENKOVA, IRINA E. VLASOVA, ANNA ROMANCHUK AND STEPAN KALMYKOV

Lomonosov Moscow State University

Presenting Author: rzhevskaia.a@gmail.com

Since the beginning of nuclear tests mankind has been facing the problem of the environment contamination with radionuclides. One of the most urgent and important tasks is to investigate the radionuclide forms of presence in the contaminated environmental objects, including the liquid radioactive waste storage reservoirs. Such water reservoirs are unique and their study is of great interest as radionuclides are homogeneously distributed and, over the years, their own biota, unlike other natural water pools, has formed. On the other side it is not always possible to get access to such sites, in these cases it is necessary to simulate natural conditions of radionuclides penetration and distribution into soils and bottom sediments.

One of the most convenient and accessible methods of radionuclide partitioning in natural objects is the sequential extraction, which involves serial treatment of soil samples with chemical reagents that selectively dissolve a certain part of the soil (mineral, organic substances, etc.) containing radionuclides. Each subsequent reagent must either be more aggressive than the previous one or of a different nature. In previous work [1] we researched speciation of uranium in contaminated sediments from the "Mining and Chemical Combine" (Zheleznogorsk, Russia) using sequential extraction, spectroscopic and microscopic methods that confirmed main state is $\mathrm{U}(\mathrm{VI})$ in predominantly easily-accessible form.

In this work we investigate different schemes of partitioning of $\mathrm{Cs}, \mathrm{Sr}, \mathrm{Am}, \mathrm{Pu}, \mathrm{U}, \mathrm{Np}, \mathrm{Co}$ in samples from contaminated areas and try to interpret this information for better understanding on the mobility of radionuclides and the possibility of their distribution in the environment. The Tessier procedure [2] was used as the basis and the reagents, its concentrations, exposure time and temperature were varied. To simulate natural conditions, we carried out sorption of radionuclides on different types of minerals and soils with known composition.

This work was supported by the Russian Science Foundation (project 19-73-20051) and Interdisciplinary Scientific and Educational School of Moscow University «Future Planet and Global Environmental Change».

[1] A. Rzhevskaia, A. Romanchuk, I.Vlasova et al. J. Env. Rad. 229-230, 106539 (2021).

[2] A. Tessier, P. G. Campbell, M. Bisson, Anal. Chem. 51, 844 (1979). 